\title{
(Incorporating) Adjunct Displays: a Step toward Facilitation of Reading Comprehension
}

\author{
Hamideh Marefat and Shima Ghahari \\ University of Tehran
}

Received: 14 February 2008 / Accepted: 12 June 2008

ISSN: $1697-7467$

\begin{abstract}
Two types of adjunct displays, graphic organizer and outline, were compared with text display to determine which one facilitates text comprehension by L2 learners. The results indicated the superiority of adjunct displays. However, no difference was observed between graphic organizers and outlines. Also it was found that low proficiency learners benefited from adjunct displays more than high proficiency ones. The results support the pedagogical potential of adjunct displays as text facilitators. The findings are discussed within the framework of the theories behind adjunct display effect.

Key words: Adjunct display effect, graphic organizer, outline, reading comprehension, expository texts.
\end{abstract}

\section{INTRODUCTION}

In order to get around language learners' age-old problem of struggling to comprehend expository texts, researchers in the field have explored ways to render implicit concept relations in such texts more explicit. Expository texts are mainly characterized by presenting abstract categories and embodying abundant inter-related concepts and relational information. The design of expository texts is in a way that «prescribes a fixed processing route and makes it difficult for a reader to encode multiple concept relations simultaneously» (Bera \& Robinson, 2004, p. 381), which, consequently, according to Cognitive Load Theory (CLT), imposes heavy cognitive demands on working memory (Katayama \& Robinson, 2000). Given their ubiquitous presence in expository texts, concepts and concept relations should be successfully processed and perceived so that the readers can construct a coherent representation and comprehend what the text is about (Pretorius, 2006).

Adjunct displays have been largely studied in recent years as a potential breakthrough in easing out the problems associated with comprehending expository texts. They represent objects, concepts, and their relations by the use of symbols and their spatial arrangements (McCrudden, Schraw, Lehman \& Poliquin, 2007). Robinson and Schraw (1994) distinguished two types of displays: sentential displays, which «consist of sequential propositions» and diagrammatic displays (p. 400).

Two of the displays which have recently been given the number one priority by both researchers to study and materials developers to include in textbooks are 'graphic organizers' and 'outlines'. Over the past decades, a host of studies (Robinson \& Schraw, 1994, Kiewra, Kauffman, Robinson, Dubois, \& Staley, 1999) have shown that these two displays, due to their 
highly convenient and reader-friendly format, have a great potential for fostering the processing of relational information and facilitating comprehension and memory for the corresponding text and, therefore, can promote meaningful learning (Kester, Lehnen, Van Gerven \& Kirschner, 2006).

Motivated by the above observations, this study focuses on two displays of outline and graphic organizer (GO, henceforth) and seeks to investigate if these adjunct displays can prove effective for L2 readers of English; and in case they are found to be effective, the study further investigates which of the displays, i.e., outline or graphic organizer, as compared to text display, is more effective for Iranian L2 English readers.

\section{A brief REVIEW OF STUdies INTO ADJUNCT DiSPlays}

In recent years a main concern of educational practitioners has been to find solutions to the difficulties the students have, both in L1 and L2, in comprehending content area textbooks. Text comprehension, as proposed by Robinson (1998), involves «learning concepts [which] define attributes, recognizing defining attributes when presented with a range of examples, learning hierarchical and coordinate relations among concepts [also known as structural knowledge] and finally, transferring this knowledge by correctly identifying concepts given new examples» (p. 86). Some of the problems with understanding texts during reading may be due to the student. For example, inability in drawing inferences across sentences or lack of contentrelevant knowledge may place heavy demands on their available cognitive resources (Bjorklund \& Harnishfege, 1990). But some of the comprehension errors can be attributed to the nature of the text itself, for example poor organization or structure can inhibit learning important between-concept relations (Robinson, 1994). In order to improve reading comprehension, two approaches, therefore, could be attempted: approaches that focus on activities performed by the reader and those by the author.

One approach that has been used to overcome poor text structure - the other being, as introduced by Robinson and Kiewra (1995), text restructuring - is the use of 'adjunct aids' or 'adjunct displays' that are inserted in text. Adjunct displays can be simply defined as those supportive materials used along with text, which include only important text information and which differ in their formats and in the way they communicate ideas. They are claimed to hold tremendous potential for helping readers 'see' the unseen phenomenon that lies within text (Robinson, 2002) by clearly and efficiently representing multiple intra- and inter-concept relations for the reader to view at a single glance (Kiewra et al., 1999).

\subsection{Typology of adjunct aids}

Adjunct aids are of two types: inside-the-text (internal) and outside-the-text (external) adjunct aids. Examples of the former include bold typing or underlining keywords. And the latter include pictures, geographic maps, concept maps, graphic organizers (GOs), outlines, advance organizers and the like (Robinson, Robinson, \& Katayama, 1999). This latter category is also called adjunct display.

Adjunct displays can be further divided into two categories: linear adjunct displays, i.e., those that appear in prose or list format and may be understood by viewing their elements in only one order or direction such as outlines, listings or summaries and spatial adjunct displays, 
i.e., two-dimensional displays of text information that may be understood by viewing their elements in any order or direction such as pictures, graphic organizers, diagrams, concept maps, etc. (Robinson et al., 1999).

\subsection{Theories behind Adjunct Display Effect (ADE)}

The students recall text information better when they are provided with the text accompanied by an adjunct display (AD) than when they are given but the text. This phenomenon is referred to as adjunct display effect (ADE) (Darsh \& Gersten, 1986). Different hypotheses explaining the ADE include: 1. Selective Cued Hypothesis; 2. Conjoint Retention Hypothesis; 3. Visual Argument and Computational Efficiency Hypothesis; 4. Search Efficiency Hypothesis.

\subsubsection{Selective Cued Hypothesis}

As proposed by Mayer (1984), 'selective cued hypothesis' holds that students will attend to and recall more of the information referenced in the displays because it is presented twice, once in the text and once in the displays. This hypothesis, therefore, does not explain why spatial adjunct displays are, in most cases, more effective in text recall than the linear ones. Numerous studies, Robinson and Kiewra (1995) taken as one, have revealed that it is the format of spatial displays and not their content that is facilitative.

\subsubsection{Conjoint Retention Hypothesis}

Another hypothesis explaining the retrieval advantage of adjunct displays is the «conjoint retention hypothesis» (CRH) proposed by Kulhavy, White, Topp, Chan and Adams (1985). This theory is associated with Paivio's dual coding theory as well as working memory model of Baddeley et al. focusing on the notion that textual information referenced in a display is dually encoded in memory, both verbally and spatially (Paivio, 1983), whereas text information that is not referenced in an adjunct display is encoded only in verbal format. Certainly information that is encoded conjointly is more likely to be retrieved because «the spatial representation provides an additional node that may be activated after an initial attempt to retrieve the verbal representation fails» (Robinson, Katayama \& Fan, 1996, p. 222).

$\mathrm{CRH}$, however, has recently been criticized for the way it explains knowledge representation (Pezdek, Roman, \& Sobolik, 1986). Pezdek et al. found evidence that «spatial information may not be encoded with the memory representation of words» (p. 95).

\subsubsection{Visual Argument and Computational Efficiency Hypothesis}

The third hypothesis explaining the facilitative encoding advantage of spatial displays is referred to as visual argument by Waller (1981, as cited in Robinson et al., 1999) and computational efficiency hypothesis by Larkin and Simon (1987): «Visual argument occurs when relations among objects are learned simply by viewing the relative location of those objects in twodimensional space» (p. 40). Computational efficiency occurs when readers are able to quickly and easily compute concept relations and to encode those relations so that they can quickly and easily be retrieved later (Winn, 1990). 


\subsubsection{Search Efficiency Hypothesis}

Apart from being computationally efficient, adjunct displays have also been argued to be search efficient or effective in locating information (Guthrie, 1989, \& O'Donnell, 1993). There are two types of search tasks: local and global search. In the former search task, a specific fact is located. The latter search type, however, involves «computing relationships among several categories of information» and is called global search (or abstraction). Global search is primarily involved in understanding the 'main idea' of text which requires several facts to be located and then to compute the relationship thereof (Guthrie, Weber, \& Kimmerly, 1993). Larkin and Simon (1987) assert that adjunct displays are more search efficient (both locally and globally) than text (Robinson \& Skinner, 1996)

\subsection{Adjunct displays and their effectiveness in L2 contexts}

Thus far, however, few studies, e.g., Coward, Robinson and Hsu (2004) and Kato and Okamoto (in Press), have been conducted over the cross-linguistic effect of the adjunct displays and their effectiveness in EFL contexts. Having conducted a comparative study, Coward et al. reported that in terms of comprehension Taiwanese students outperformed American students when provided with adjunct displays. They further observed that graphic organizers were better than knowledge maps (another type of adjunct displays) for both Taiwanese and American students. Overall, they found Taiwanese students more successful in benefiting from the adjunct displays.

Kato and Okamoto (in Press) conducted a study to examine the effect of utilizing visual information of charts and diagrams in academic Japanese text reading. The results of their study, in contrast with the previous one, yielded little advantage for Japanese university students in using visual information of charts and diagrams, as the students could not grasp the whole structure of a scientific text effectively. The explanation they provided for this finding was that charts and diagrams embedded in texts might interrupt the reading comprehension of nonnative readers.

These contradicting findings leave some room for further research on the potential effectiveness of text adjuncts for EFL learners. This has been attempted in this study by investigating into the effect of two displays of outline and graphic organizer, in comparison with text display, on decreasing cognitive load and bolstering comprehension and memory for the text information for Iranian EFL learners.

\section{RESEARCh QUESTIONS}

The current research is guided by the following questions:

1. Do adjunct displays, as compared to text display, bear any facilitative effect in comprehending L2 expository texts by Iranian EFL learners across different proficiency levels?

2. Is there any difference between outlines, as linear displays, graphic organizers, as spatial displays, and text displays in improving L2 expository text comprehension by Iranian EFL learners across different proficiency levels? 


\subsection{Method}

\subsection{Participants}

A total of 91 students (both male and female) from five different classes participated in this study for some course credit. The average age of the participants was 21 . They were all B.A. students of English Language and Literature studying at University of Tehran and Azad University of Karaj. Having administered a TOEFL test, the scores were pruned and then the participants were split into two proficiency-level groups: high and low. By so doing, the number of participants reduced to $71 ; 42$ fell into the high-level group and 29 into the lowlevel group.

\subsection{Materials}

The current study involved two sets of instruments: 1) A TOEFL test (ETS, 2004) for determining the participants' level of language proficiency and 2) Adjunct displays materials.

The adjunct displays materials used in this study were taken from Katayama and Robinson (2000). The original materials, however, were modified, in the sense that the length of the texts, the number of the displays and the test items were reduced to a considerable degree.

Upon making these modifications, three sets of materials of the present study were developed. Each set included a text, an outline, a GO and a test consisting of ten four-option multiple-choice fact items. The texts in each set had a different topic and focused on a specific type of sleep disorder. Number of words in each text ranged from 600 to 1000 typed on singlespaced pages. For each text there followed an outline and a GO, which were constructed to be informationally equivalent to each other. Finally, a memory test which included ten fouroption multiple-choice comprehension questions measuring knowledge of hierarchical and coordinate concept relations was administered.

\subsection{Procedure}

Initially, a TOEFL test was administered. Afterwards, the participants in each class received a text to read. They were instructed to read the text for details because the text would be collected before they received the test.

Having submitted the texts, the participants were randomly assigned to three groups, one receiving the same text, one its GO and one the outline of the text they had read. Those in the latter two groups were briefed that these GOs and outlines were based on the texts they had studied and would help them in answering the questions that would follow. These materials were then collected and the participants started the testing part of the experiment which included ten multiple-choice questions. The whole procedure was conducted in 110 minutes.

\subsection{Design}

This study entails two independent variables: language proficiency with two levels, low vs. high, and display type with three levels: text, outline and graphic organizer. The dependent variable in this study is the learners' scores on the reading comprehension test. 


\section{RESUlts}

The first research question was addressed by testing the following null hypothesis: there is no difference between adjunct displays and text display in comprehending L2 texts by EFL learners across different proficiency levels.

Table 1 below depicts descriptive statistics for adjunct displays and text display across the two proficiency levels. As can be seen, adjunct displays are very effective in improving the participants' performance.

Table 1: Descriptive Statistics for the Text Display vs. Adjunct Displays across Proficiency Levels

\begin{tabular}{lcccc}
\hline Display type & Level & Mean & Std. Deviation & $\mathrm{N}$ \\
\hline \multirow{2}{*}{ Adjunct displays } & High & 8.500 & 1.606 & 26 \\
& Low & 8.333 & 2.221 & 21 \\
& High & 7.187 & 2.286 & 16 \\
Text display & & & & \\
& Low & 4.125 & 2.031 & 8 \\
\hline
\end{tabular}

In order to test the above-mentioned hypothesis, a two-way ANOVA was conducted. The results revealed a significant effect for display type $\left(\mathrm{F}_{(1,67)}=27.59, \mathrm{p}<.05\right)$. This implies that the type of display the participants viewed as supportive materials had a strong effect on their comprehension. A significant main effect for level $\left(\mathrm{F}_{(1,67)}=9.441, \mathrm{p}<.05\right)$ was also observed. The interaction between display type and level of proficiency had a significant effect $\left(F_{(1,67)}\right.$ $=7.593, \mathrm{p}<.05)$. In other words, adjunct displays were more helpful for students with low proficiency; their mean improved from 4.12 to 8.33 .

The second null hypothesis to be tested was: there is no difference between outlines, graphic organizers and texts in improving L2 text comprehension. Table 2 provides descriptive statistics for proficiency level and the three displays. As it is displayed in the table, the mean values for both types of adjunct displays (i.e. GO and outline) are significantly higher than that of text display for both proficiency levels. In fact, text display seems not to be as efficient as either outlines or GOs in facilitating text comprehension. No such difference, however, is observed between GO and outline displays.

Table 2: Descriptive Statistics for Display Types (GO, outline and text) across Proficiency Levels

\begin{tabular}{cllll}
\hline Level & Displays & Mean & Std. Deviation & $\mathrm{N}$ \\
\hline \multirow{3}{*}{ High } & GO & 9.000 & 1.322 & 9 \\
& Outline & 8.235 & 1.715 & 17 \\
& Text & 7.187 & 2.286 & 16 \\
& & & & \\
\multirow{2}{*}{ Low } & GO & 8.769 & 1.739 & 13 \\
& Outline & 7.625 & 2.825 & 8 \\
& Text & 4.125 & 2.031 & 8 \\
\hline
\end{tabular}


To ensure that the differences observed in Table 2 are statistically significant and in order to comparatively assess the effect of the three displays (GO vs. outline vs. text), a two-way ANOVA was conducted.

The proficiency level had a significant main effect $\left(\mathrm{F}_{(1,65)}=6.796, \mathrm{p}<.05\right)$. Display type factor also showed a highly significant main effect $\left(\mathrm{F}_{(2,65)} \stackrel{1}{=} 14.635, \mathrm{p}<.05\right)$. The interaction between proficiency level and display type was also significant $\left(\mathrm{F}_{(2,65)}=3.148\right.$ and $\left.\mathrm{p}<.05\right)$.

Since the display type factor has three levels, a post-hoc Scheffe test was conducted to see where exactly this difference lies. The results revealed that graphic organizer and text display bear a statistically significant difference $(\mathrm{p}<.05)$. Outline too is significantly superior to text display $(\mathrm{p}<.05)$. Yet, no significant difference was observed between the two adjunct displays, that is to say that graphic organizer and outline groups have brought about similar performances on the test.

\section{Discussion}

Two research questions were investigated through this study. First, we asked whether adjunct displays allow for better text comprehension than text displays do; and whether the two levels took advantage of the adjunct displays to the same degree. The findings evidenced that graphic organizers and outlines were more efficient than text as they produced significantly higher scores on comprehension test. Still, one could argue that this superior performance could be attributed to adjunct displays' content rather than their format as they included only partial text information. However, there is evidence, e.g., Kato and Okamoto (in Press), that adjunct displays would no more than text itself contribute to text comprehension and processing by Japanese EFL students. Moreover, Kiewra et al. (1999) refute the claim that the observed differences between text display and adjunct displays are likely the result of 'information availability', or what we above considered as 'content mismatch'. They carried out an experiment in which they highlighted the exact topics, categories and details appearing in adjunct displays - in that study outlines and matrices - and used roughly the same number of words. They reported that even when the students were told that the highlighted portion was all they needed to study for test, their performance mirrored the text-only group and fell below that of students' studying outlines and matrices. This finding, firstly, showed that selective attention to highlighted text ideas was not sufficient for text and concept relations processing. And therefore, it established that what was important about adjunct displays such as outlines and matrices was their physical organization. «[Text adjuncts] use fewer words and physically organize ideas by topics and categories so that relations among ideas are more discernible» (Kiewra et al., 1999, p. 396). This is precisely what visual argument and computational efficiency hypothesis adheres to, that format and physical organization of adjunct displays are in a way that one could easily and most efficiently compute and encode concept relations simply by viewing their location and the way they are arranged on the page relative to each other. Secondly, this finding of Kiewra et al.'s study could justify the ample number of follow-up studies which have been conducted on the facilitative advantage of different adjunct displays.

Another finding in the present study was that graphic organizers and outlines contributed more to low proficiency students than to high proficiency ones. A viable explanation for this could be that low proficiency students, due to their low proficiency as well as less experience and expertise in text reading, find supplementary reading materials and activities very helpful, 
and naturally take advantage of such tools and resort to them in order to compensate for their reading and second language deficiencies.

The second research question concerned in this study was whether the type of display the students viewed would differentially affect the students' performance on the comprehension test. The results indicated that text display was not as efficient as either outline or graphic organizer displays. This provides counter evidence for Selective Cued Hypothesis and suggests that presenting information twice is not the only key to the success of adjunct displays and other factors, e.g., their format, may be involved in rendering them superior to text display.

Moreover, no difference was observed between GOs and outlines, that is, the participants performed similarly across these two display conditions. This finding, consequently, does not fit with Conjoint Retention Hypothesis, proposed by Kulhavy et al. (1985), which favors spatial displays over linear ones, holding that the former are dually (verbally and spatially) represented in memory.

\section{IMPLiCATIONS}

The findings of this study are in line with research literature which shows that adjunct displays play a significant role in helping students comprehend more text information and process more concept relations, i.e., Visual Argument and Computational Efficiency Hypotheses. The findings, however, contradict previous studies which found GO, a spatial display, superior to outline which is a linear display, i.e., Conjoint Retention Hypothesis.

The results, moreover, seem to call into question the Selective Cued Hypothesis which reasons that the effectiveness of text adjuncts in processing more text information lies in the fact that the information is presented twice, once in the text and once in the displays. This study included, in addition to adjuncts groups, a text-only group and the results showed that the latter group did not perform as the other two groups though they too received the information twice. Thus the Selective Cued Hypothesis could safely be rejected.

The results are also compatible with Cognitive Load Theory (CLT). Consistent with previous research, this study also established that GOs and outlines reduced the amount of effort needed to get the intended message and to locate information. This reduction in effort and study time is what is supported by CLT and what holds appeal for instructional designers (Robinson \& Schraw, 1994).

Therefore, educators and materials developers are encouraged to incorporate appropriate text adjuncts, when needed, to help students learn inter-concept relations, understand the whole structure and do well on comprehension and memory tests.

Moreover, educators can be recommended to encourage and train the students, while doing note-taking as a post-reading activity, to construct their own notes in GO and outline formats. In so doing, students are likely to recall more text information and perform better on tests as they review the notes that they themselves have recorded. The above applications could hold appeal for materials developers, too. 


\section{REFERENCES}

Bera, S. J. \& Robinson, D. H. (2004). Exploring the boundary conditions of the delay hypothesis with adjunct displays. Journal of Educational Psychology, 96: 381-388.

Bjorklund, D.F., Harnishfeger, K.K. (1990). The resources construct in cognitive development: Diverse sources of evidence and a theory of inefficient inhibition. Developmental Review, 10: 48-71.

Coward, F. L., Robinson, D. H., \& Hsu, C. (2004). The role of cultural background in using adjunct displays. Research in the Schools, 11: 35-41.

Darsh, C., \& Gersten, R. (1986). Direction-setting activities in reading comprehension: A relation of two approaches. Learning Disabled Quarterly, 9: 235-243.

Guthrie, J. T. (1988). Locating information in documents: Examination of a cognitive model. Reading Research Quarterly, 23: 178-199.

Guthrie, J. T., Weber, S., \& Kimmerly, N. (1993). Searching documents: Cognitive processes and deficits in understanding graphs, tables, and illustrations. Contemporary Educational Psychology, 18: 186-221.

Katayama, A. D. \& Robinson, D. H. (2000). Getting students «partially» involved in note-taking using graphic organizers. Journal of Experimental Education, 68: 119-133.

Kato, Y. \& Okamoto, T. (in Press). The effects of utilizing visual information of charts and diagrams in academic Japanese text reading. Retrieved from the Web July 6, 2001. http://www.eec.kumamoto-u.ac.ip/THET01/proc/123.pdf.

Kester, L., Lehnen, C., Van Gerven, P. W. M., \& Kirschner, P. A. (2006). Just-in-time, schematic supportive information presentation during cognitive skill acquisition. Computers in Human Behavior, 22: 93-112.

Kiewra, K. A., Kauffman, D. F., Robinson, D. H., Dubois, N. F., \& Staley, R. K. (1999). Supplementing floundering text with adjunct displays. Instructional Science, 27: 373-401.

Kulhavy, R. W., White, M. T., Topp, B. W., Chan, A. L., \& Adams, J. (1985). Feedback complexity and corrective efficiency. Contemporary Educational Psychology, 10: 285-291.

Larkin, J. H. \& Simon, H. A. (1987). Why a diagram is (sometimes) worth ten thousand words. Cognitive Science 11: 65-99.

Mayer, R.E. (1984). Aids to text comprehension. Educational Psychologist 19: 30-42.

McCrudden, M. T., Schraw, G., Lehman, S., \& Poliquin, A. (2007). The effects of causal diagrams on text learning. [Electronic version]. Contemporary Educational Psychology, 32: 367-388.

O'Donnell, A. (1993). Searching for information in knowledge maps and texts. Contemporary Educational Psychology, 18: 222-239.

Paivio, A. (1983). The empirical case for dual coding. In J. C. Yuille (Ed.) Imagery, memory and cognition. Hillsdale, NJ; Erlbaum, 310-332.

Pezdek, K., Roman, Z., \& Sobolik, K. G. (1986). Spatial memory for objects and words. Journal of Experimental Psychology: Learning, Memory, and Cognition, 12: 530-537.

Pretorius, E. J. (2006). The comprehension of logical relations in expository texts by students who study through the medium of ESL. System, 34: 432-450.

Robinson, D. H. \& Kiewra, K. A. (1995). Visual argument: Graphic organizers are superior to outlines in improving learning from text. Journal of Educational Psychology, 87: 455-467.

Robinson, D. H. \& Molina, E. (2001). The relative involvement of visual and auditory working memory when studying adjunct displays. Contemporary Educational Psychology, 27: 118131. 
Robinson, D. H. \& Schraw, G. (1994). Computational efficiency through visual argument: Do graphic organizers communicate relations in text too effectively? Contemporary Educational Psychology, 19: 399-415.

Robinson, D. H. \& Skinner, C. H. (1996). Why graphic organizers facilitate search processes: Fewer words or computationally efficient indexing? Contemporary Educational Psychology, 21: 166-180.

Robinson, D. H. (1994). Textbook selection: Watch out for 'inconsiderate' texts. In K. Prichard \& M. Sawyer (eds.), Handbook of college teaching. Westport, CN: Greenwood, 415-422.

Robinson, D. H. (1998). Graphic organizers as aids to text learning. Reading Research and Instruction, 37: 85-105.

Robinson, D. H. (2002). Spatial text adjuncts and learning: An introduction to the special issue. Educational Psychology Review, 14: 307-309.

Robinson, D. H., Robinson, S. L., Katayama, A. D. (1999). When words are represented in memory like pictures: Evidence for spatial encoding of study materials. Contemporary Educational Psychology, 24: 38-54.

Winn, W. D. (1990). A theoretical framework for research on learning from graphics. International Journal of Educational Research, 14: 553-564. 